\title{
Os desafios da empregabilidade dos haitianos na hotelaria de Florianópolis
}

\section{The challenges of Haitian employment in the Florianópolis hotels}

\section{Hurildes Agostinho}

Discente no curso Superior de Tecnologia em Hotelaria do Instituto Federal de Educação, Ciência e Tecnologia de Santa Catarina - IFSC, Florianópolis/SC, Brasil E-mail: guinhadoreco@gmail.com

\section{Tiago Savi Mondo}

Professor efetivo de Turismo do Instituto Federal de Educação, Ciência e Tecnologia de Santa Cataria - IFSC, Florianópolis/SC, Brasil

E-mail: tiago.mondo@ifsc.edu.br 


\section{RESUMO}

A inserção profissional no mercado de trabalho é sempre uma honra para qualquer trabalhador, nesse sentido, este trabalho teve como objetivo analisar em que condições de empregabilidade os imigrantes haitianos estão em relação à hotelaria de Florianópolis. Esta pesquisa caracteriza-se por ser exploratória, descritiva, quantitativa, do tipo pesquisa de campo. Para a coleta de dados foi utilizado questionário fechado com sete gestores de hotéis de Florianópolis, além disso, analisaram-se sessenta currículos de imigrantes haitianos. Sendo que, ao final, obtiveram-se os seguintes resultados: os haitianos que estão nos hotéis deixam uma impressão diversificada para alguns gestores e, quase a totalidade é positiva, tanto para o desempenho, vontade de aprender coisas novas, vontade de se firmar no emprego, tirando assim, o turnover da hotelaria e suas habilidades linguísticas, as quais são de grande valia. Mas, por outro lado, a pesquisa apontou que somente um gestor fez menção à falta de higiene pessoal desses imigrantes, bem como, em situações nas quais precisava ser chamada a atenção, não aceitavam de bom grado, fazendo com que todos do grupo, também, sentissemse repreendidos, e isso fez com que dificultasse possíveis contratações. Todavia, de forma geral, os resultados foram positivos, colocando essa força de trabalho em evidência no cenário do mercado hoteleiro.

Palavras-chave: Empregabilidade. Florianópolis. Hotelaria. Imigração Haitiana.

\section{ABSTRACT}

The professional insertion in the labor market is always an honor for any worker. In this sense this work had as objective to analyze in what conditions of employability the Haitian immigrants are in relation to the hotel of Florianópolis. This research is characterized by being exploratory, descriptive, quantitative, type of field research. For the data collection, a closed questionnaire was used with seven managers from Florianópolis Hotels, in addition, sixty curricula of Haitian immigrants were analyzed. In the end, the following results were obtained: the Haitians in the hotels leave a diversified impression for some managers, and almost all of is positive, both for performance, willingness to learn new things, willingness to stand on the employment, thus taking the hospitality turnover and language skills, which are of great value. On the other hand, the research pointed out that only one manager made mention of the lack of personal hygiene of these immigrants, and in situations in which they needed to be noticed, they did not accept willingly, making everyone in the group also, felt rebuked, and this made it difficult to hire potential. But in general, the results were positive, putting this workforce in evidence in the hotel market scenario.

Keywords: Employability. Florianópolis. Hospitality. Haitian Immigrants. 


\section{INTRODUÇÃO}

O Haiti é um País com uma superfície de 27.500 km - o que equivale a 9,8 vezes menor que o território do Rio Grande do Sul -, além disso, é considerado "uma nação insular, a qual se localiza entre o mar do Caribe e o Oceano Atlântico, ocupando o terço Ocidental da ilha de Hispaniola; e a República Dominicana ocupa os dois terços Orientais”. (Background on Haiti, 2010, p. 03).

Dessa forma, conforme preceitua Diamond (2005), o Haiti é considerado o país mais pobre do hemisfério ocidental, bem como um dos mais pobres do mundo, ficando atrás, somente, de alguns países do continente africano. Além desse fato, o Haiti é um dos países com maior densidade populacional. Quanto à forma de subsistência, vale lembrar que muitas pessoas que lá residem não têm emprego ou renda fixa, ou seja, vivem do comércio informal. E, no que tange à taxa de crescimento anual da população, esta é de $2,08 \%$, o que significa mais de 11 milhões de pessoas para alimentar até o ano de 2020. Por conseguinte, a explosão demográfica e a crise econômica são fatores que desestruturam o mundo rural, o que propicia a vinda maciça deles para as grandes cidades, e também para os países vizinhos.

Com tudo isso, percebe-se que o povo haitiano ainda vive em extrema pobreza, sem infraestrutura adequada, o que faz com que muitas pessoas que lá residem, pensem em deixar o seu país de origem e imigrar para outros países, dentre eles, o Brasil.

Conforme Dutra (2016), os haitianos vieram para algumas partes do globo pela questão da vulnerabilidade social, econômica, e também ambiental. Nesse sentido, pode-se afirmar que o fluxo migratório de haitianos para o Brasil iniciou-se de forma gradativa, após o terremoto de 2010, com magnitude sísmica de 7,3, na Escala Richter, que destruiu $80 \%$ das construções, inclusive, o Palácio Presidencial. O mesmo autor salienta ainda, que o número de mortes chegou a 300 mil pessoas, e 1,5 milhão de haitianos ficaram desabrigados, fato esse que deixou o Haiti em profunda tristeza. Tudo isso fez com que muitos imigrantes haitianos viessem tentar a sorte no Brasil, sendo que no começo entravam neste país, cerca de 10 imigrantes ilegais por dia, porém, estudos feitos apontam que o número de imigrantes chega hoje a aproximadamente de 80 a 100 por dia. O que se pode perceber é que houve um acréscimo considerável da entrada desses imigrantes em busca de melhores condições de vida.

Para Singer (2008), essas imigrações têm causas distintas, uma vez que "quem migra, leva sozinho, sonhos de uma vida melhor para si e para a sua família, quer obter sucesso econômico rápido, e quer regressar de forma vitoriosa para a sua terra natal.” (Silva, 2006, p. 157).

Assim, pode-se concluir que, o que trouxe os haitianos para essa parte do globo foi sua vulnerabilidade social, econômica, como também ambiental. (Dutra, 2016). 
Essas condições de extrema pobreza, na qual tudo ainda falta, traz consigo hábitos que por muitas vezes não se assemelham aos nossos, tais como a higiene perfeita (troca e lavagem da roupa diária), até porque muitas vezes a pouca água que eles têm é utilizada para beber, além disso, não existe a preocupação com o modo de se bem portar à mesa, já que a preocupação deles é saber se terão comida no dia seguinte. Tudo isso faz com que essa população entre em choque com os nossos ditos costumes civilizados.

De acordo com inúmeros jornais que circulam em Santa Catarina, a chegada de imigrantes haitianos no Estado ocorre desde 2010. Por conta disso, há uma grande discussão entre a Secretaria de Assistência Social do Estado e a Prefeitura Municipal, que tentam, de toda forma, acolhê-los. Para tanto, foram providenciados abrigos temporários e, em seguida, esses imigrantes foram levados à Superintendência do Ministério do Trabalho, a fim de que fosse confeccionada, pelo referido órgão, a carteira de trabalho deles.

Diante de todos esses fatos, e por entender que esses imigrantes e refugiados precisam de uma maior atenção, foi criado o Grupo de Apoio aos Imigrantes e Refugiados de Florianópolis e Região (GAIRF), em abril de 2014, pela Arquidiocese de Florianópolis.

Convém ressaltar, que hoje em dia esse grupo conta com a parceria de universidades, de igrejas, de organizações não-governamentais, bem como de representantes de algumas instituições do Poder Público. Um dos setores que pode absorver a mão-de-obra haitiana é o turismo.

Dentro deste contexto, importante é se falar que a atividade turística tem como sua matéria-prima a oferta de um conjunto de atrativos naturais e culturais, somado a isso tem-se os serviços de transporte, hospedagem, alimentação entre outros, é o que se pode chamar de produto turístico (Beni, 1998). Petrocchi (2003) afirma que o produto turístico tem alguns componentes básicos, dentre eles, destacam-se: o transporte, a hospedagem e o atrativo, aparecendo a hotelaria e o turismo como inseparáveis.

Dessa forma, os hotéis se desenvolveram durante o passar dos anos e a procura dos serviços cresceu consideravelmente em virtude de fatores como melhoria de transporte e o aumento e a disponibilidade das pessoas em viajarem (Pereira \& Coutinho, 2007). Por conta disso, os serviços de hotelaria realizaram grandes melhorias a fim de atrair os clientes, sobressaindo-se em um mercado que é cada vez mais competitivo. Em síntese, um hotel é definido como estabelecimento que deverá fornecer um bom serviço de alojamento, de refeições, bar, tratamento de roupas, informações turísticas e de caráter geral (Janeiro, 1991).

Conforme a EMBRATUR, o faturamento alcançado pelo setor turístico brasileiro como um todo, no último trimestre de 2016, superou em $37 \%$ as estimativas previamente projetadas pelo setor. Nesse mesmo entendimento, foi observado que o nível de emprego nos 
três últimos meses do ano passado superou em 38\% o que representantes da área tinham como prognóstico.

Esses dados são constatados no Boletim de Desempenho Econômico do Turismo, publicação trimestral, desenvolvida pelo Ministério do Turismo, por meio da Fundação Getúlio Vargas (FGV). Para tanto, foi feita uma pesquisa com 918 empresas, as quais representam 71.498 postos de trabalho, e apresentaram um faturamento no trimestre de $R \$ 7,8$ bilhões. Essas empresas integram sete setores, sendo eles: Transporte Aéreo, Parques e Atrações, Agências de Viagens, Meios de Hospedagem, Turismo Receptivo, Organizadores de Eventos e Operadoras de Turismo. Vale ressaltar que esse levantamento foi realizado entre os dias 2 e 31 de janeiro de 2017.

Segundo Filho (2005), no que diz respeito ao Estado de Santa Catarina, a atividade turística é uma das principais fontes de recursos financeiros de diversas localidades.

Em um curto espaço de tempo, algumas empresas catarinenses perceberam nesses imigrantes uma oportunidade de mão-de-obra para trabalhar nos mais variados setores, sendo um deles o setor hoteleiro, no qual a busca da qualidade por serviços prestados está inteiramente ligada aos seus colaboradores. Para comprovar o mencionado, a qualidade pode ser mensurada por meio de vários métodos, quais sejam: 5'S, PDCA, Controle de Qualidade Total, Diagrama de Pareto, bem como o Sistema ISO. Portanto, importante ressaltar que cada estabelecimento precisa escolher e avaliar o melhor método a fim de mensurar a qualidade dos serviços prestados pelos seus colaboradores. (Castelli, 2001).

Dessa forma, assim como preconiza Araújo (2013), constata-se que a qualidade ganha destaque cada vez maior no mercado de consumo, o que faz com que conquiste um percentual maior na economia e tenha relação direta com a satisfação do cliente, até porque, todo e qualquer investimento perpassa pelo bom empreendimento, que se tiver um diferencial, permanecerá no mercado, superando assim, toda e qualquer expectativa.

Conforme o Serviço Brasileiro de Apoio às Micro e Pequenas Empresas - SEBRAE (2000, p. 19), “a qualidade é inerente ao produto ou ao serviço mas é julgada pelo cliente".

Por conseguinte, observa-se que a qualidade diz respeito à percepção do cliente, a qual sempre será subjetiva. Por conta disso, a procura pela qualidade dos serviços hoteleiros pode ser vista como elemento impulsionador para a competitividade neste mercado.

Sob essa ótica, entende-se que a sobrevivência desse empreendimento no mercado só será possível caso as necessidades e desejos sejam totalmente sanados, uma vez que o mercado atual continua extremamente competitivo e os clientes cada vez mais exigentes. Assim, para que esses recursos sejam plenamente alcançados com sucesso, é mister investir na qualificação dos recursos humanos (colaboradores). 
Conforme Fernandes (2014), “ a maior parte desses imigrantes haitianos, no que diz respeito ao primeiro emprego, ficou na construção civil $(59,7 \%)$, seguida pelo setor de serviços gerais $(13,8 \%)$, setor industrial $(11,2 \%)$ e serviços ligados ao setor de alimentação $(7,3 \%) "$

Nesse sentido, Chapecó, Navegantes, Itajaí, Balneário Camboriú e Florianópolis são algumas das cidades que receberam esses grupos, que, no primeiro momento, foram compostos por homens jovens, e em seguida, começaram a chegar as mulheres. Ainda que a maioria dos haitianos estivesse empregado nos mais variados setores, tais como construção civil e agroindústria, percebe-se que a cidade de Florianópolis recebe um grande número de turistas estrangeiros, porém pesquisas apontam que quem os recepciona na hotelaria não está totalmente apto a falar outros idiomas para bem atendê-los e, por conta disso, observa-se que o povo haitiano possui essa habilidade já intrínseca, fazendo com que fosse de grande valia o aproveitamento dessa força de trabalho, uma vez eles já chegam prontos. Convém ressaltar que uma das grandes barreiras às quais eles precisam enfrentar é lidar com a Língua Portuguesa.

Mesmo que já tenham sido apresentados os demais tópicos, traz-se agora o questionamento que permeia o presente trabalho: A absorção da população imigrante, proveniente do Haiti, atenderia às reais exigências da qualidade dos serviços prestados pelos hotéis executivos de Florianópolis? Além disso, o objetivo geral visa analisar a empregabilidade dos imigrantes haitianos na hotelaria da Região central Florianopolitana.

\section{FUNDAMENTAÇÃO TEÓRICA}

Trazem-se agora os ensinamentos de Singh (2014), o qual afirma que a população haitiana é constituída de $95 \%$ de negros, e 5\% de mulatos; e ainda, que $33 \%$ dessa população moram nas cidades; enquanto $67 \%$ residem no campo. A cidade tem 700 pessoas por km, sendo que nascem de 3 a 4 crianças na área urbana, e sete crianças na área rural. Somente a título de curiosidade, pontua-se que os haitianos têm como expectativa de vida, 62 anos.

No que diz respeito à saúde e à infraestrutura, constata-se que quase $50 \%$ da população não têm acesso a esses direitos básicos. Inclusive a própria capital, Porto Príncipe, sofre com a falta de água e dos demais direitos universais que cabem aos cidadãos haitianos. Além disso, os problemas de água e saneamento no Haiti são enormes, tendo em vista que $45 \%$ da população não têm acesso à água potável, e $83 \%$ da população não dispõem de serviço de saneamento. Somado a isso, observa-se ainda que $60 \%$ da população são subnutridas e, uma em cada quatro crianças, sofre de retardo no crescimento. (Prospere, 2011). 
Imprescindível ressaltar que, de acordo com o relatório do Programa das Nações Unidas para o Desenvolvimento (PNUD), o Haiti contava com um dos mais baixos Índices de Desenvolvimento Humano do Mundo, IDH- medida que resume o progresso em longo prazo em três segmentos básicos do desenvolvimento humano, quais sejam: renda, educação e saúde. Ainda, de acordo com a Organização das Nações Unidas - ONU-, o País ocupa a 146a posição (Villen, 2012). Nesse sentido, segundo Zamberlam, (2014), o supracitado Relatório diz que as políticas públicas econômicas neoliberais, implantadas no Haiti, pelo Fundo Monetário Internacional (FMI), colocará a economia Haitiana no rol do subdesenvolvimento.

Assim, em virtude de todas as considerações apresentadas, constata-se que o Haiti, sendo um País de dimensões pequenas, se comparadas a cidades do nosso território nacional, conta com uma população negra em grande número, chegando inclusive, a quase $100 \%$, e que essa população ainda vive em áreas distantes da cidade, e em condições básicas de vida extremamente precárias.

Por outro lado, ressalta-se que o Haiti está muito próximo de um dos destinos mais cobiçados de todo o mundo: o Caribe. E mesmo com toda essa movimentação turística, a distribuição de renda no Haiti não é igualitária, até mesmo porque os haitianos trabalham de maneira informal, não tendo, portanto, uma renda fixa.

Esses imigrantes chegam, com o objetivo de que o governo brasileiro promova oportunidades a eles, os quais se originam de um país politicamente instável, com uma economia defasada, e que busca, no Brasil, um possível recomeço de vida, razão pela qual faz-se necessária a imigração.

Germani (1974) considera que, para se obtiver um estudo eficaz sobre o fenômeno migratório, importante compreender não só os fatores que fizeram os imigrantes deixarem sua terra-mãe, mas também analisar toda a trajetória, avaliar as condições culturais, sociais e econômicas, tanto do país de origem, quanto do país ao qual se pretende migrar.

Assim, após o tremor de 2010 o qual ocasionou um grande desastre no Haiti, o que deixou o país devastado e sem expectativa de vida, os haitianos começaram a se refugiar em outras terras sendo uma delas o Brasil.

Conforme relatos, no ano de 2011 e início de 2012, cerca de 10 imigrantes ilegais por dia chegavam ao Brasil de forma tímida, entretanto, no ano de 2015, o número cresceu consideravelmente, perfazendo um total de 80 a 100 imigrantes ilegais por dia. Assim, segundo o Ministério das Relações e Exteriores, o número de haitianos em solo brasileiro ultrapassa a casa de 50 mil.

Evidencia-se, também, que o número de imigrantes provenientes do Haiti para o Brasil é dinâmico, somente variando no tempo e no espaço, pois consoante dado do Conselho 
Nacional de Imigração (CNIg), órgão esse, colegiado e vinculado ao Ministério do Trabalho e Emprego (MTE), no ano de 2010 foram concedidos vistos de permanência somente para quatro haitianos: já, em 2011 foram 709 vistos; em 2012, foram 4.682 e, até junho 2013 foram 870 vistos.

Imperioso salientar que os haitianos que procuram o Brasil com intuito de reconstruir suas vidas, possuem, em sua maioria, algum grau de qualificação profissional, logo não são pessoas iletradas e sem preparo; muitos deles possuem curso técnico, curso superior, e falam inclusive, até três idiomas, entre eles o Espanhol e o Francês.

A respeito da qualificação desses imigrantes é comum encontrar pessoas com ensino superior no Haiti ou na República Dominicana impossibilitados de exercerem sua profissão no Brasil, pois o processo de validação dos seus diplomas é, o que os impede de alcançarem posições mais vantajosas no mercado de trabalho e assim garantir uma melhor renda. Tal dificuldade ainda é também associada às limitações com o idioma da Língua Portuguesa, e isso se pode constatar pelo entendimento de Fernandes e Ribeiro que dizem:

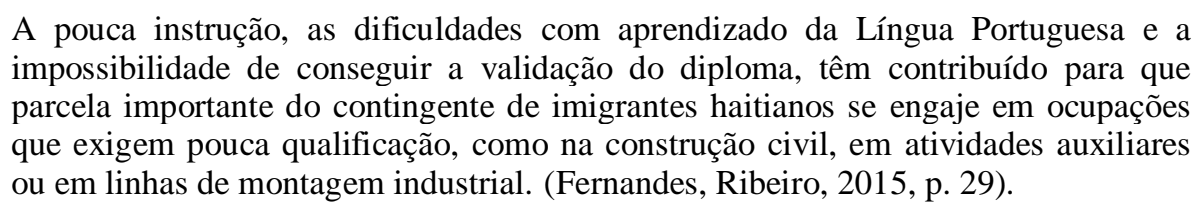

Por outro lado, o mercado brasileiro de trabalho os explora como mão-de-obra barata, e muitas vezes eles não têm seus direitos trabalhistas assegurados por estarem ilegais.

Como o Brasil é liderança na Missão das Nações Unidas para a estabilização no Haiti (Minustah, 2010), o povo haitiano observa as inúmeras organizações não-governamentais brasileiras que já atuaram no terremoto de 2010 e que atuam até hoje, o que torna o Brasil, aos olhos dos haitianos, um país acolhedor. A princípio, os imigrantes solicitam refúgio, alicerçados no Direito Internacional dos Refugiados e na Legislação Brasileira, bem como no Conselho Nacional de Refugiados (CONARE), todavia os motivos que eles trazem, quais sejam: desastre natural e estado de miserabilidade, não se enquadram na perseguição atribuída ao Direito Internacional, tampouco na legislação vigente no Brasil. Mas, no momento que já estavam em solo brasileiro, o CONARE passou ao Conselho Nacional de Imigração (CNIg) que concedeu o visto humanitário para que o imigrante haitiano pudesse trabalhar e também estudar no Brasil, obviamente não seriam somente esses os desafios dos imigrantes haitianos no Brasil, todas as outras mazelas e dificuldades de um cidadão ficam evidentes quando esses imigrantes chegam ao território brasileiro.

Inicialmente, convém apontar que os refugiados no Brasil enfrentam as mesmas dificuldades que os nacionais, resultantes da pobreza e das desigualdades sociais que atingem a maioria da população nacional. A precária qualidade no atendimento aos serviços de Saúde 
e de Educação também atingem os refugiados, bem como as habitações inadequadas, e isso permanece uma questão de difícil solução.

Por conta disso, a imigração haitiana requer uma análise da realidade vivenciada por esse grupo, o qual está em condições de vulnerabilidade. Exemplo disso, destaca-se a duração da viagem, os custos, o visto humanitário, dentre outros fatores.

Por outro lado, e não menos importante, está a composição da imigração no Brasil, a qual se configura parte fundamental para o crescimento e para o desenvolvimento econômico do País; todavia, o desconhecimento da Língua Portuguesa é um dos entraves que impedem a comunicação de muitos imigrantes, seja para se alimentar, pedirem emprego, compreender as normas trabalhistas, ou até mesmo, fazer uso do Sistema de Saúde, dentre outras situações que possam ocorrer.

De acordo com Cotinguiba e Pimentel (2012), que afirmam: os haitianos, em termos linguísticos, caracterizam-se como diglóssicos, isto é, são indivíduos bilíngues. Eles se comunicam no interior do grupo apenas no crioulo haitiano, que é o idioma predominante de 95\% da população haitiana; e 5\% da população fala o francês, considerado uma língua de elite, um status, sinônimo de poder econômico e social, porém, entendida pela maioria e, ainda, um número bastante reduzido de indivíduos fala inglês.

Por conta disso, eles estão sempre juntos, formando guetos, e que existe um verdadeiro choque cultural, logo, a adaptação desses imigrantes se torna um processo lento e demorado.

Além dos obstáculos elencados, relativos às dificuldades de adaptação e de comunicação, existem ainda situações invisíveis dentro do contexto social imigratório no Brasil, sendo elas a difusão de preconceitos e discursos que propagam a xenofobia, ou seja, a aversão a pessoas de origem estrangeira.

Em suma, no Ordenamento Jurídico brasileiro, para exemplificar, estão previstos no art.3ㅜ, inciso IV, da Constituição Federal de 1988, os objetivos fundamentais da República, em especial o de “... promover o bem de todos, sem preconceitos de origem, raça, sexo, cor, idade, e quaisquer outras formas de discriminação".

Corroborando com a presente pesquisa, traz-se parte da entrevista que a Secretária de Assistência Social do Estado de Santa Catarina concedeu, em maio de 2015, ao Jornal Diário Catarinense: Ainda que os serviços prestados pelo Poder Público e pela sociedade sejam importantes, é dever do governo catarinense criar políticas públicas para acolher esses imigrantes. Prefiro não acreditar que o Poder Público catarinense tenha se esquecido de suas origens, de quem o ajudou a construir nosso Estado, e menos ainda não quero supor que ele lembre apenas da parte branca e rica da história. 
Além disso, em nota publicada no Jornal Diário Catarinense, o Prefeito César Souza Júnior também manifestou sua indignação face à chegada dos imigrantes na capital, dizendo que:

Em um futuro não muito distante, não seja mais necessário que a mídia faça um alarde pela chegada dos coirmãos, pois o povo catarinense e quase a sua totalidade é filho de imigrante, sendo assim, é importante ter um olhar generoso, pois ele agora está em uma situação que o próprio Brasil já viveu.

Por ora, necessário estabelecer a importância do turismo como possibilidade empregatícia para esses imigrantes haitianos. E, com relação a isso, a qualidade dos serviços adquire um lugar especial na luta pela competitividade, mesmo que a relação com a Educação, a formação e o mundo do trabalho inexista. Com isso, para a adequação às exigências da economia global, houve uma rápida modificação das organizações, o que não mais dá a garantia de emprego desse colaborador se aposentar em uma única empresa.

Segundo Chiavenato (2009) "com a nova visão do mercado e do trabalho, houve uma profunda mudança no contrato de trabalho e, em consequência, a quebra do vínculo trabalhista, desestabilizando a relação entre empresa e empregado", dependendo de cada um a administração de sua carreira. Diante desse entendimento, já existe incentivo para que as pessoas tenham formação continuada com conhecimentos amplos e de inúmeras qualidades, permitindo adentrarem em variados segmentos com o intuito de facilitação de sua empregabilidade.

Corroborando com o supracitado, percebeu-se que as mudanças no perfil do mundo do trabalho são os motivos primordiais para que haja o avanço de novas habilidades, atitudes e competências, elementos que podem ser observados nos imigrantes haitianos que chegam com tais qualidades inerentes a eles, tornando-os aptos a serem inseridos no mercado de trabalho.

Dessa forma, os hotéis se desenvolveram durante o passar dos anos e a procura dos serviços cresceu consideravelmente, em virtude de fatores como melhoria de transporte e o aumento e a disponibilidade das pessoas em viajarem (Pereira \& Coutinho, 2007). Por conta disso, os serviços de hotelaria realizaram grandes melhorias a fim de atrair os clientes, sobressaindo-se em um mercado que é cada vez mais competitivo.

Nesse sentido, os empreendimentos hoteleiros, influenciados pela grande exigência do cliente, bem como pela competitividade cada dia mais acirrada desse setor, continuam trabalhando de forma a melhorar a qualidade dos serviços que oferecem (Cândido \& Vieira, 2003).

Corroborando com os autores supracitados, traz-se o entendimento de Berry e Parasuraman (1995), que dizem que os clientes avaliam a qualidade do serviço prestado, 
comparando o que desejam ou que esperam, com aquilo que eles têm. Assim, o ideal é que a satisfação dos clientes no que diz respeito à prestação de serviços ultrapasse as suas expectativas, que é mensurar o espaço existente entre o que se pensa e o que se quer, desejando um resultado positivo para a organização.

Segundo Castelli (2003), o cliente se sente satisfeito quando percebe que suas necessidades, bem como seus desejos, são atendidos por meio de bens e serviços de qualidade. Ainda sobre o tópico acima, Hoffman e Bateson (2003), a curto prazo, faz-se e análise se o cliente está satisfeito; em contrapartida, somente a longo prazo é que o cliente dará o diagnóstico da qualidade do serviço prestado, fato esse que diferencia uma empresa de seus concorrentes. Segundo Filho (2005), no que diz respeito ao Estado de Santa Catarina,

\begin{abstract}
a atividade turística é uma das principais fontes de recursos financeiros de diversas localidades, pois por vários anos a atividade ficou em segundo plano na elaboração de políticas públicas em todas as esferas. A partir do início da década de 1990, com o crescimento dos orçamentos dos órgãos do setor, a participação do turismo na economia cresceu consideravelmente, tendo em vista que começou a ser encarada pelo Estado como uma possibilidade de combate ao desemprego, de geração de renda, de distribuição de recursos e de ingresso de divisas do exterior - neste último caso tendo relação com a política econômica que privilegia o superávit da balança comercial.
\end{abstract}

Sendo assim, traz-se o questionamento que permeia o presente trabalho: A absorção da população imigrante, proveniente do Haiti, atenderia às reais exigências da qualidade dos serviços prestados pelos hotéis executivos de Florianópolis? E, como objetivo geral buscou-se analisar a empregabilidade dos imigrantes haitianos na hotelaria da região central florianopolitana.

\title{
3. PROCEDIMENTOS METODOLÓGICOS
}

\subsection{Naturezas da pesquisa}

Conforme Fernandes e Gomes (2003) verifica-se que a definição do delineamento metodológico que é utilizado no presente trabalho é tão, ou mais importante, quanto definir os objetivos e o problema de pesquisa, uma vez que ambos estão interligados.

Para o presente estudo, buscou-se a pesquisa quantitativa que é aquela que trata do emprego da quantificação, tanto nas modalidades de coletas de informações, quanto no tratamento delas, por meio de técnicas estatísticas. (Richardson, 1999). Dessa forma, para Mattar (2001), com esse tipo de pesquisa, busca-se a validação das hipóteses, mediante a utilização de dados estruturados, estatísticos, e com a análise de um grande número de casos representativos. Ainda, sobre esse tópico, traz-se o entendimento de (Malhotra, 2001), “A 
pesquisa quantitativa procura quantificar os dados e aplicar alguma forma de análise estatística".

Nesse sentido, o referido autor ainda cita que na pesquisa quantitativa, a determinação da composição do tamanho da amostra é o processo no qual a estatística tornou-se um meio principal. (Malhotra, 2001).

Para que fosse feita a análise da população (imigrantes haitianos), buscou-se o GAIRF, que é Grupo de Apoio a Imigrantes e Refugiados em Florianópolis e Região, bem como a Pastoral do Imigrante (Arquidiocese de Florianópolis), a qual possui filiais na Faculdade Municipal de Palhoça e em Santo Amaro da Imperatriz. Salienta-se que o primeiro contato foi efetuado via telefone, e em seguida foi enviado um e-mail solicitando currículos para servir como amostras para a referida pesquisa, o que foi prometido prontamente. Todavia, as Instituições precisam de um tempo para organizar os currículos. Após essa solicitação, houve uma demora de aproximadamente 1 ano e 3 meses, ou seja, desde Agosto de 2016 até Setembro de 2017, tempo esse que prejudicou o andamento da pesquisa.

Em virtude dessa morosidade, buscou-se outra fonte de informação, sendo ela a Faculdade Municipal de Palhoça. No primeiro momento, prometeu-se a entrega de grande quantidade de currículos, no entanto, apenas vinte currículos foram enviados (via e-mail) para o pesquisador. Conforme já pontuado, foram analisados sessenta currículos, sendo os quarenta restantes conseguidos pela governança do hotel no qual o pesquisador estagiou.

\subsection{População e amostra}

No que tange a população, esta será composta, exclusivamente, por imigrantes haitianos que vieram no ano de 2010, tendo uma crescente entre 2012 a 2015, para o Estado de Santa Catarina, e também para a cidade de Florianópolis. Dessa forma, no que diz respeito ao tópico da amostra, será feita uma análise de currículos, confeccionados por profissional da área de Recursos Humanos da Pastoral do Imigrante.

Convém ressaltar, que alguns desses currículos foram fornecidos pela Gerência de Governança do Hotel em que este Acadêmico fez o seu estágio.

Além disso, os Gestores Hoteleiros responderam a sete questionários em formato de um roteiro semiestruturado de entrevista, que consoante explica Manzini (2003) é aquela em que é possível um planejamento de coleta de informações, mediante a elaboração de um roteiro com perguntas que atinjam os objetivos pretendidos. Assim sendo, se na pesquisa estruturada o entrevistador segue um roteiro rígido, com perguntas-padrão; na entrevista semiestruturada, de acordo com (May, 2004), a diferença central “é o seu caráter aberto", ou seja, o entrevistado responde as perguntas dentro de sua concepção, mas não se trata de deixá- 
lo falar livremente. Até porque o pesquisador não deve perder de vista o seu foco. Já, para (Gil, 1999, p. 120) "o entrevistador permite ao entrevistado falar livremente sobre o assunto, entretanto, quando este se desvia do tema original, esforça-se para a sua retomada". Portanto, verifica-se que nesta técnica, o pesquisador não pode se utilizar de outros entrevistadores para realizar a entrevista, pois é imprescindível que o entrevistado tenha pleno conhecimento do assunto.

\subsection{Procedimentos de coleta}

Conforme já mencionado no segmento amostra, um dos instrumentos de levantamento de dados utilizados foi a análise apurada dos currículos dos imigrantes haitianos, dos quais constam dados pessoais, tais como: gênero, idade, estado civil, nacionalidade, conhecimentos linguísticos, área de atuação, grau de escolaridade e experiências profissionais anteriores.

O segundo segmento analisado, tratou de um roteiro semiestruturado de entrevista online, o qual foi respondido prontamente por sete (7) Gestores Hoteleiros.

Para a elaboração desse instrumento de pesquisa, utilizou-se a ferramenta Google Forms que facilitou a construção do presente questionário.

\section{ANÁLISE DE RESULTADOS}

Como já comentado anteriormente, para fundamentar a pesquisa foram necessários alguns procedimentos de Coleta de Dados e um dos procedimentos foi a análise de sessenta currículos, estes, na sua maioria, deixados na recepção dos hotéis, dos quais foram extraídos dados relevantes para o trabalho. Convém ressaltar que todos os currículos deixados são de origem haitiana. Assim, passa-se agora a descrição dos dados encontrados:

Quanto ao Gênero: foram 34 Masculinos e 26 Femininos.

Sobre a Média de Idades: esta variou bastante, ficando entre 24 e 34 anos, o que demonstra que são adultos jovens que procuram Florianópolis para se estabelecer.

Em relação ao Estado Civil: os currículos apontaram que 90\% são solteiros, e somente $10 \%$ são casados, assim fica evidenciado que a possibilidade de estabelecer vínculos familiares aqui é bem grande, possibilitando uma miscigenação não somente de raça, mas também de costumes.

Quanto à Nacionalidade: $100 \%$ são Haitianos, porém não havia informação da cidade de onde se originaram.

Em relação aos Conhecimentos Linguísticos: a fonte primária desta pesquisa aponta que $100 \%$ têm mais de um idioma falante, variando um pouco no grau de fluência, indo do 
Inglês Básico até o fluente; bem como com o Espanhol, além de $100 \%$ falarem com fluência o Francês e, como língua nativa, o Criolo.

No tocante à Área de Atuação: neste quesito também há uma grande diversidade, que vai desde a área da Construção Civil, Engenharia Elétrica, passando pelos Setores Hoteleiros, quais sejam: Governança, Recepção, Manutenção, Camareiras e Serviços Gerais.

Quanto à Formação Acadêmica: esta varia do ensino médio completo até o nível superior. Os currículos também apontam que boa parte já chega com formação superior completa, todavia, alguns procuram faculdades em solos brasileiros para concluírem seus estudos. $\cdot$

Em relação às Experiências Profissionais Anteriores: na sua maioria, todos trazem uma vasta bagagem em diversos setores, até mesmo com os setores com os quais eles já se correlacionam, por isso a procura acaba sendo direcionada para sua a formação. Mas, por outro lado, os haitianos ressaltam que caso não conseguem uma colocação na sua área de atuação, mas que estão abertos a novas experiências no campo do trabalho.

Nesse sentido, não bastou somente a análise dos currículos desses haitianos, buscou-se também a visão dos gestores hoteleiros. Para tanto, foi desenvolvido um questionário que foi respondido pelos gestores e que apresentou os resultados que seguem:

\subsection{Resultados das pesquisas com os gestores hoteleiros}

Foi enviado um Questionário Eletrônico, do qual se obteve a resposta de sete (7) Gestores, sendo seis (6) da cidade e Florianópolis, e um (1) da cidade de São José.

Quanto à Categoria dos Hotéis: dois Hotéis são de categoria Executiva, dois de categoria Econômica, um de categoria Executiva de Média Escala, um de categoria de Média Escala, e um de Média Escala Lazer e Negócios.

No tocante à Localização: de acordo com o que já foi relatado, seis são da Região Central de Florianópolis, perpassando pela Beira-Mar Norte, chegando até o Bairro do Itacorubi; e pelo lado do continente, na cidade de São José.

Quanto ao Número de Funcionários: os resultados também apresentam uma variação que vai de 26 funcionários a 86 funcionários.

Em relação ao Número de Unidades Habitacionais: os resultados apontam uma variação que vai de 88 , o menor número e 200 , o maior número, ficando explícito que esse referido número depende muito do porte do estabelecimento hoteleiro, bem como de sua categoria. 
Quanto ao fato de Receber Haitianos Para Entrevista de Trabalho: quase a totalidade dos gerentes afirma que recebem; mas um gestor deixou claro que não recebe ou recebeu.

Em relação à Experiência com os Haitianos no Local de Trabalho: os resultados apontam que existe uma visão parcialmente positiva, pois os gerentes pontuam que, no início, esses haitianos são proativos, contudo, acabam tendo alguns problemas de relacionamento com os seus colegas de serviço, já que, como eles têm por costume viver em grupos, trazem isso para o convívio trabalhista. Dessa forma, alguns gestores relataram que esse tipo de comportamento dificulta a convivência com a equipe. Outro fator mencionado por um dos gestores diz respeito à higiene pessoal dos haitianos, uma vez que esta não se iguala à nossa, o que resulta, muitas vezes, na não-contratação. Sob essa óptica, convém ressaltar que essa ação, pode ser considerada como Preconceito. (grifo meu).

Quando abordado o termo higiene, traz-se o pensamento de Gioppo, (1996), o qual diz que o termo higiene deriva da eugenia que tem essa mudança entre os séculos XIX e o $\mathrm{XX}$, e que dentre outros objetivos busca doutrinar os trabalhadores das fábricas para uma orientação de higiene padrão.

Esse pensamento que nasceu na Era Industrial na Inglaterra e nos Estados Unidos, chegou ao Brasil com menos força, porém essa segregação e essa possibilidade de domesticação dos menos favorecidos, fez com que os mesmos criassem hábitos higiênicos conforme o padrão que lhes foi imposto, evitando assim a aglomeração, o dormir em camas separadas, e o isolamento do público para o privado.

Tal contexto se baseia no preconceito, no isolamento, na padronização, haja vista que as individualidades são colocadas de lado, não se importando com cada cidadão, como ser único e até pertencente a um grupo, que tem seus costumes, suas crenças, seus hábitos.

Assim sendo, no papel de gestor deve-se ter o cuidado para não absorver e estabelecer um pré-conceito sobre qualquer indivíduo.

Em relação às Qualidades Apresentadas pelos Haitianos que Trabalham nos Hotéis destacam-se: humildade, vontade de aprender novas tarefas, disponibilidade vinculada à necessidade de trabalhar por compromissos familiares, tanto aqui, como no Haiti. Sobre essa questão, um gerente aponta que nem sempre demonstram ter pró-atividade, mas fazem questão de se estabelecer na empresa, pois inibe o turnover que é muito comum no meio hoteleiro.

No tocante às Dificuldades Apresentadas pelos Haitianos: os gerentes são unânimes em dizer que a falta de conhecimento da Língua Portuguesa é uma barreira a ser ultrapassada, dando aos haitianos uma negatividade para compreender e executar tarefas mais complexas. 
Até mesmo deixando-os cientes do conhecimento de Leis Trabalhistas e, consequentemente, dos seus direitos, ficando por vezes à mercê da bondade ou da honestidade do empregador. Outro fator que chama atenção trata do fato de não reagirem bem a feedbacks negativos, deixando uma linha tênue entre ficar, ou não na empresa, por não se adaptarem às diretrizes..

Em referência aos Outros Funcionários em Receber estes Haitianos: todos os gerentes afirmam que os que já estão na casa, não têm problema nenhum, o que configura uma convivência pacífica.

Em relação a Algum Programa de Inserção Exclusivo para os Haitianos os gerentes respondem que não existe, ou seja, os haitianos têm os mesmos treinamentos que são oferecidos a todos os outros funcionários.

No que diz respeito à Função que os Haitianos Procuram: os resultados são para Governança, Serviços Gerais, A\&B e Cozinha e Camareira. Como se pode perceber, os resultados não apontaram a procura para função de recepcionista, tampouco para cargos com maior envergadura.

Sabe-se que o Haiti é um país que vem passando por sérias dificuldades, isso faz com que muitos habitantes daquele país, busquem condições melhores de sobrevivência, sendo que, por vezes, são obrigados a deixarem seu país de origem, tendo o Brasil como um dos destinos mais procurados para se estabelecer, embora as condições de trabalho oferecidas em solo brasileiro não sejam as mais favoráveis.

Conforme Dutra, (2016) os haitianos vieram para algumas partes do globo pela questão da vulnerabilidade social, econômica, e também ambiental.

Assim, a presente pesquisa teve como objetivo analisar a empregabilidade dos imigrantes haitianos na hotelaria de Florianópolis.

Em se tratando de empregabilidade, constatou-se que existem ainda muitas barreiras a serem transpostas, começando pela parte linguística a qual diz respeito a eles não falarem a Língua Portuguesa, mesmo que falem bem outros idiomas, dificultando, assim, o diálogo com os outros colaboradores.

O presente trabalho apontou, com os resultados obtidos, que por mais que alguns haitianos sejam absorvidos na hotelaria, isso ainda não tem grande expressão, já que os cargos procurados por eles, bem como os oferecidos pelos empreendimentos hoteleiros, normalmente são operacionais. Deixa-se claro, aqui, que esses haitianos vislumbram cargos gerenciais ao longo do tempo, tendo em vista que uma das menores escolaridades é o ensino médio completo, porém boa parte deles possui graduação completa.

Os resultados ainda apontam que no quesito experiência com os haitianos, os gestores afirmam que ao começarem na empresa, os haitianos não têm grandes problemas, entretanto, 
com o passar do tempo as questões de relacionamento com a equipe prejudicam o andamento da empresa, pois eles têm por costume criar seu próprio círculo social, fazendo com que não haja uma aproximação deles com outros colegas.

Tudo isso, não difere muito das crises que os brasileiros têm de relação interpessoal, configurando mais uma vez um preconceito e um não-conhecimento das relações que esses haitianos estabelecem com os seus.

\section{CONSIDERAÇÕES FINAIS}

O trabalho teve como escopo analisar a empregabilidade dos haitianos na hotelaria de Florianópolis, empregabilidade essa que tem como intuito, não só uma colocação no mercado de trabalho, que seria comum para os brasileiros, mas para os imigrantes, no caso os haitianos, significa um recomeço, pois traduz um momento de superação por todas as adversidades que essa população passou e continua passando.

População, esta que após o Terremoto de 2010 se viu em plena destruição e com perdas gigantescas, seja no campo social, estrutural da cidade com a destruição de aldeias inteiras, com o abalo no seu sistema político e, sobretudo, na sua economia, o que fez com que um dos países mais pobres do mundo não conseguisse se reerguer, a ponto de muitos haitianos deixarem sua terra natal para se aventurarem em outro país. E foi com a visão de prosperidade e por toda a divulgação feita pelas mídias televisionadas, jornalísticas e agora sociais, que o Brasil é conhecido como um país acolhedor e cheio de oportunidades.

Contudo, a busca por colocação passa também pelo setor hoteleiro, até mesmo porque essa população chega a Florianópolis com grau de instrução muitas vezes elevado, e ainda, com uma visão internacional de turismo, até porque muitos apontaram em seus currículos conhecimentos turísticos, seja no atendimento, seja na habilidade linguística que eles possuem.

Com uma carga horária de 8 horas diárias, e uma escala de seis por um, muitos colaboradores não conseguem sair para se aperfeiçoar, e a convivência com a população haitiana, pela sua multiculturalidade, poderia ser aproveitada, já que existem poucos brasileiros que falam outros idiomas, e os imigrantes poderiam contribuir, em muito, para esse aprendizado. 
Nesse sentido, os imigrantes podem se beneficiar dessas habilidades e conhecimentos para galgar postos mais expressivos na hotelaria, embora alguns deles já cheguem com graduação, e outros a busque aqui. Assim, importante dar ciência a eles do potencial que têm potencial, este que só vai aparecer se forem acompanhados de forma maciça e séria, com a orientação para o mercado de trabalho. Esse é o papel das Instituições de Ensino.

A parte gerencial dos empreendimentos hoteleiros, após ter esse conhecimento, poderia incentivar a contratação para que essa população efetivamente entrasse na hotelaria, e com a ajuda dos gerentes ficaria facilitada a contratação desses imigrantes em cargos mais expressivos.

Como em toda pesquisa, houve dificuldades, em especial, as limitações foram que as instituições que detêm os acompanhamentos dessa população colaboraram, em parte, para a liberação de dados, haja vista que embora solicitados, por muitas vezes, via telefone, e-mail, e por documentação formal, não disponibilizaram informações, como por exemplo, currículos. Convém salientar que alguns currículos foram conseguidos pelos gerentes de recepção e governança, que mantêm arquivados esses documentos.

Outra notificação é que seja pela grande quantidade de chegada desses imigrantes, ou por falta de pessoal, sendo que a maioria é de voluntários, os dados estão desorganizados e desatualizados, como por exemplo, currículos feitos sem padronização, dados relevantes não aparecem, como os gêneros, não sendo possível definir, e assim por diante, deixando as informações conseguidas por muitas vezes sendo interpretadas tão somente pelo pesquisador.

Assim sendo, uma possibilidade de pesquisa seria como esses dados e informações são disponibilizadas e quais providências são tomadas com os dados gerados, como são aproveitados, dados estes de grande relevância para uma política social eficaz. Outra possível pesquisa seria como inserir essa população no cotidiano da cidade, estabelecer qual a real colaboração dos imigrantes na constituição da nossa sociedade.

Como enfrentarmos os preconceitos pela falta de conhecimentos dos outros costumes em uma cidade turística, multicultural e extremamente miscigenada?

Nesse contexto é importante sabermos que a responsabilidade dessa inserção dos imigrantes haitianos cabe a cada um de nós, para uma melhor integração dos que aqui vêm para se firmar em nossa cidade, para que todos possam viver em harmonia, deixando de lado diferenças culturais, sociais, raciais, e que não sejamos mais surpreendidos com um ato tão comum, que é o fato de imigrar.

\section{REFERÊNCIAS}


Araújo, V. M. G. de. (2013). Qualidade dos serviços na Hotelaria: um estudo na Rede de Hotéis Alfa, 132.

Background on Haiti. (2010). Haitian Health Cultural. A Cultural Competence Primer from Cook Ross Inc.

Beni M. C. (1998). Análise estrutural do turismo. São Paulo: SENAC.

Berry, L. L., \& Parasuraman, A. (1995). Serviços de marketing: competindo através da qualidade. São Paulo: Maltese, Brasil. Ministério do Trabalho e Educação. CNIg. Recuperado em 02, janeiro, 2015, de http://portal.mte.gov.br/imprensa/estudo-analisa-migracao-haitianano-brasil.htm

Cândido, I., \& Vieira, E. V. (2003) Gestão de hotéis: técnicas, operações e serviços. Caxias do Sul: EDUCS.

Castelli G. (2001). Administração Hoteleira. (8a ed.). Caxias do Sul: EDUCS, 732p.

Castelli G. (2003). Administração hoteleira. (9a ed.). Caxias do Sul: EDUCS.

Cotinguiba G. C., \& Pimentel, M. L. (2012) Apontamentos sobre o processo de inserção social dos haitianos em Porto Velho. Travessia- Revista do Migrante, 99-106.

Chiavenato, I. Talento e empregabilidade. In: Instituto Chiavenato/ Apostila. Recuperado em 15, maio, 2009, de www.prh.ufma.br/apostilas/3chiavenato_talento

CLICRBS. ANotícia. (2014). Haitianos chegam ao Estado com formação superior e idiomas. Recuperado em 08, maio, 2017, de http://anoticia.clicrbs.com.br/sc/noticia/2014/01/haitianoschegam-ao-estado-com-formacao-superior-e-idiomas-4404206.html

Diário Catarinense. Prefeito de Florianópolis irá formalizar protesto por chegada de haitiano. Recuperado em 06, outubro, 2015, de http://diariocatarinense.clicrbs.com.br/sc/geral/noticia/2015/05/prefeito-de-florianopolisiraformalizar-protesto-por-chegada-de-haitianos-4767404.html

Diamond, J. (2005). Colapso - Como as sociedades escolhem o fracasso ou o sucesso. Editora RCB.

Dutra, C. F. (2016) Além do Haiti: uma análise da imigração haitiana para o Brasil. Rio de Janeiro: Lumen Juris,

Instituto Brasileiro de Turismo. (2016). Faturamento do turismo nacional no último trimestre de 2016 supera em 37\% estimativas do setor. Recuperado em 24, novembro, 2017, de http://www.turismo.gov.br/\%C3\%BAltimas-not\%C3\%ADcias/7621-faturamento-do-turismonacional-no-\%C3\%Último-trimestre-de-2016-supera-em-37-estimativas-do-setor.html

Instituto de Migrações e Direitos Humanos. (2006). A atuação pastoral junto aos refugiados no Brasil. Recuperado em 10, fevereiro, 2006, de www.migrante.org.br/textoseartigos.htm

Fernandes, D., \& Gomes, M. C. (2003). A imigração dos haitianos para os países da América do Sul: desafios de política migratória no trajeto e no destino. 
Fernandes, D., \& Ribeiro, J. C. (2015). Migração laboral no Brasil: problemáticas e perspectivas. Cadernos Obmigra, 1(1), 15-37.

Filho, V. L. (2005). Estudo do fluxo de informações em centros de informações turísticas de Santa Catarina: Programa Portais do Lazer. Florianópolis, 134f. Dissertação (Mestrado em Ciência da Informação) - Universidade Federal de Santa Catarina. Florianópolis.

Germani, G. (1974). Sociologia da modernização: estudos teóricos, metodológicos e aplicados a América Latina. São Paulo: Mestre Jou.

Gil, A. C. (1999). Métodos e Técnicas de Pesquisa Social. São Paulo: Atlas.

Gioppo, C. (1996). Eugenia: a higiene como estratégia de segregação. Curitiba.

Grupo de Apoio ao Imigrante e Refugiado de Florianópolis e Região. (2015). Novos Imigrantes e Refugiados na Região da Grande Florianópolis: Observações preliminares sobre suas experiências e demandas. Florianópolis.

Hoffman K. D., \& Bateson, J. E. G. (2003). Princípios de marketing de serviços: conceitos estratégias e casos. São Paulo: Pioneira Thomson Learning.

Hora de Santa Catarina. Clic Rbs. (2015). "Nosso povo é filho de imigrantes e precisa ser generoso com o tema", diz Ângela Albino sobre estrangeiros em SC. Recuperado em 06, outubro, 2015, de http://horadesantacatarina.clicrbs.com.br/sc/geral/noticia/2015/05/nossopovo-e-filho-deimigrantes-e-precisa-ser-generoso-com-o-tema-diz-angela-albino-sobreestrangeiros-em-sc4767699.html

Malhotra, N. (2001). Pesquisa de marketing. (3a ed.) Porto Alegre: Bookman.

ManziniI, E.J. (2003). Considerações sobre a elaboração de roteiro para entrevista semiestruturada. In: Marquezine: M. C., Almeida, M. A. \& Omote, S. (Orgs.) Colóquios sobre pesquisa em Educação Especial. Londrina: eduel, 11-25.

Mattar, F.N. (2001). Pesquisa de marketing. (3a ed.) São Paulo: Atlas.

May, T. (2004). Pesquisa social: questões, métodos e processos. (3a ed.) Porto Alegre: Artmed.

Ministério do Trabalho e Emprego. (2013). Recuperado em 30, junho, 2013, de http://portal.mte.gov.br/geral/estatisticas.htm

Minustah. (2010). As motivações e as consequências de uma operação liderada pelo Brasil. Fortaleza: Monografia, 74.

Petrocchi, M. (2003). Agências de turismo: planejamento e gestão. São Paulo: Futura. 
Pereira, A. H. R. (2007). O Componente Militar da Missão das Nações Unidas para a Estabilização do Haiti. Military Review, edição brasileira, jan-fev, 02-13.

Pereira, F. F., \& Coutinho, H. R. M. (2007). Hotelaria: da era antiga aos dias atuais. Revista Eletrônica Aboré, Publicação da Escola Superior de Artes e Turismo.

Programa das Nações Unidas para o Desenvolvimento. (2014). "Haiti" na estrada para a resistência às catástrofes. Recuperado em 10, junho, 2014, de www.ht.undp.org/content/haiti/fr/home/ourperspective/ourperspectivearticles/2014/05

/26/Haiti-sur-le-chemin-de-la-resilience-aux-desastres

Prospere, R., \& Martin, A. G. (2011). País .A questão ambiental no Haiti: um desafio na reconstrução do País. Revista Eletrônica em Gestão, Educação e Tecnologia Ambiental. REGET-CT/UFSM. 3(3).

Richardson, R. J. et al. (1999). Métodos quantitativos e qualitativos. Pesquisa social: métodos e técnicas, 3, 70-89.

Serviço Brasileiro de Apoio às Micro e Pequenas Empresas. (2000). Princípios da Qualidade. (2a ed.) Porto Alegre: SEBRAE, I.

Silva, S. A. da. (2006). Bolivianos em São Paulo: entre o sonho e a realidade. Estudos Avançados, 20, (57).

Singer, P. (2008) Economia política da urbanização. (2a ed.) São Paulo: Contexto.

Singh, B., \& Cohen, M. J. (2014). Climate change resilience the case of Haiti. University of Montréal/Oxfam América. Oxfam Research Reports.

Villen, P. (2012) Polarização do mercado de trabalho e a nova imigração internacional no Brasil. In: Seminário do Trabalho: Trabalho e Políticas Sociais no Século XXI.

Zamberlam, Jurandir et al. (2014). Os novos rostos da imigração no Brasil - Haitianos no Rio Grande do Sul. Porto Alegre. Solidus.

\section{FORMATO PARA CITAÇÃO DESTE ARTIGO}

AGOSTINHO, H., \& MONDO, T. S. (2018). Os desafios da empregabilidade dos haitianos na hotelaria de Florianópolis. Revista de Turismo Contemporâneo, 6(2), 189-210. 